\title{
As relações de poder que se configuram nas compras em universidades públicas: contribuição para os estudos dos documentos e da materialidade da informação
}

\author{
Nadi Helena Presser \\ Doutora; Universidade Federal de Pernambuco, Recife, PE, Brasil \\ nadihelena@uol.com.br \\ Nadja Macêdo de Araújo \\ Mestre; Universidade Federal Rural de Pernambuco, Garanhuns, PE, Brasil \\ nadjamaraujo@yahoo.com.br \\ Juliene da Silva Barros Gomes \\ Doutora; Universidade Federal Rural de Pernambuco, Garanhuns, PE, Brasil \\ julienesb@hotmail.com
}

\begin{abstract}
Resumo: Este artigo analisa as relações de poder que se configuram nos mecanismos de disciplinarização e de regulação do processo de compras de uma universidade pública federal, como contribuição para os estudos da materialidade dos documentos, no processo informacional. O procedimento técnico de coleta dos dados contou com o mapeamento do processo, além da realização de entrevistas semiestruturadas com os servidores públicos envolvidos e do levantamento dos documentos legais e institucionais que normatizam e orientam o fluxo de trabalho. O processo foi analisado e interpretado por meio de duas perspectivas: a disciplinar - mediante contribuição da teoria foucaultiana; e a documental - com ênfase no caráter social e material da informação, linha teórica frohmanniana. A análise do poder disciplinar revelou como as práticas sociais e institucionalizadas por meio de documentos produzem um conjunto de conceitos promissores para pensar filosoficamente sobre informação. A razão para essa conclusão é de que a atenção às práticas e aos documentos revela como documentos específicos, em determinados momentos e lugares e em áreas específicas do terreno institucional, social e cultural, tornam-se informativos, materializados e se conformam como mecanismos disciplinares.
\end{abstract}

Palavras-chave: Processo de Compras. Universidades Públicas. Poder Disciplinar. Documentação. Informação. 


\section{Introdução}

Tradicionalmente, autores descrevem a organização como um sistema de autoridade formal em termos de um organograma, distribuído numa estrutura "vertical" ou "horizontal", na autoridade formal e legítima (VOLKEMA et al., 2016; MINTZBERG, 2008; PERROW; THOMPSON; PETERSON, 1970).

Foucault (1988) denominou essa visão usual do poder como jurídicodiscursiva, concepção na qual o poder foi idealizado como algo que é constituído por pessoas ou por instituições. Por conseguinte, na concepção usual, o poder é ascendido pela posição ou pelo cargo que uma pessoa ocupa, que reprime e proíbe, que pode ser comandado de forma racional (SILVEIRA, 2005).

Segundo Maia (1995), o primeiro traço que interessa destacar na analítica foucaultiana sobre o poder é o abandono de uma visão tradicional em que sua atuação se basearia fundamentalmente em seus aspectos negativos: proibindo, censurando, interditando, reprimindo, coagindo. $\mathrm{O}$ motivo de o poder ser aceito na sociedade está relacionado ao fato de ele ser uma força que não diz somente não (FOUCAULT, 1988; 2017). Por isso, a analítica de poder foucaultiana estuda o poder como algo que possui existência própria e formas específicas em um grau mais elementar (MACHADO, 2017).

De acordo com Foucault (1987), a necessidade de adestrar os corpos e de gerir as populações ocasionou o desenvolvimento das instituições de disciplina. Como uma mecânica do poder, segundo Silveira (2005), a disciplina define como se pode ter domínio sobre o corpo dos outros, não simplesmente para que façam o que se quer, mas para que operem como se quer, com as técnicas segundo a rapidez e a eficácia que se determina.

A disciplina implica um registro contínuo de conhecimento, pois, ao mesmo tempo em que exerce um poder, produz um saber. Por isso, de acordo com Frohmann (2008), Foucault (1987) mostra que a documentação tem um poder constitutivo, diferentemente de sua função apenas comunicativa. $\mathrm{Na}$ análise de Frohmann (2008), o processo que Foucault (1987) chama de "escrita disciplinar" coloca indivíduos num campo de vigilância por meio da inserção de registros sobre eles em circuitos institucionais altamente rotinizados. De fato, se 
observarmos os diversos dispositivos legais vinculados a um processo de compras públicas, vemos como o governo gera as próprias regras que regulam as atuações dos servidores públicos. Há a definição da atividade a ser feita, da tarefa a ser executada e da norma a ser seguida. Para a organização, cabe somente determinar as metas e regular os fluxos internos a fim de facilitar que os servidores cumpram o que regras estabelecem.

Nas considerações de Frohmann (2008),

O 'poder da escrita' que 'captura e fixa' indivíduos não é o poder de apenas transcrever características objetivas individuais préexistentes na forma escrita, portanto permitindo que 'informações' sobre os indivíduos sejam comunicadas. (FROHMANN, 2008, p. 8).

Ao contrário, o poder da escrita é “[...] uma parte essencial dos mecanismos da disciplina.”, é o aparelho disciplinar por intermédio do qual "[...] indivíduos são construídos como objetos de conhecimento." (FROHMANN, 2008, p. 8). Também o corpo é colocado como alvo de incidência do poder, uma vez manipulado, modelado, adestrado, não somente no que diz respeito às proibições, mas para se adequar a um sistema que produz hábitos e forma sujeitos de ação e de conhecimento.

Assim, o interesse de Foucault não é na documentação como um meio de comunicação de informação, mas como transmissão de poder gerativo e formativo, por meio do qual "indivíduos que podem ser conhecidos são constituídos institucionalmente.” (FROHMANN, 2008, p. 8). É com esse entendimento que Frohmann (2008) argumenta que a informatividade de um documento depende de certos tipos de práticas que esse documento leva com ele, porque a informação emerge como um efeito de tais práticas. Isto é, o documento nomeia a materialidade da informação.

Nesse contexto, o objeto deste estudo são as relações de poder que se configuram na execução dos processos de compras de materiais de consumo em uma universidade pública federal, cujo nome será preservado. Para isso, o foco da análise são as relações que se estabelecem entre a Unidade Solicitante (que pode ser um centro acadêmico, uma unidade acadêmica avançada, um departamento) e os demais agentes da universidade federal que fazem parte 
diretamente do processo. $\mathrm{O}$ processo estudado foi escolhido devido às similaridades dos trâmites em todas as universidades federais. Altamente regulado por meio de um conjunto de documentos, por um lado, é um processo essencial às universidades, por outro, envolve seus participantes em disputas de poder que operam coagindo-os ininterruptamente, em suas mais ínfimas atitudes e hábitos no trabalho.

Isso posto, o objetivo deste artigo é analisar as relações de poder que se configuram nos mecanismos de disciplinarização e de regulação do processo de compras de uma universidade pública federal, como contribuição com os estudos da materialidade dos documentos, no processo informacional.

Para a Ciência da Informação, o tema é oportuno porque contribui com recursos teóricos e práticos para pensar sobre como a materialidade dos documentos e dos seus enunciados pode configurar a vida organizacional. De modo igual, mostra como conjuntos de documentos são utilizados e se tornam a expressão simbólica do poder nas organizações, transformando-se eles mesmos em mecanismos disciplinares.

\section{A configuração do poder disciplinar nas organizações}

Para Foucault (2017), impõe-se uma mudança no enfoque do poder, observando seu exercício menos em termos jurídicos e de proibição e mais como técnicas e estratégias com efeitos produtivos. Assim, o filósofo aponta para uma nova percepção desse fenômeno. Isto é, o poder não deve ser conhecido como algo detido por uma classe dominante que o teria conquistado, afastando a participação e a atuação dos dominados. Ao contrário, as relações de poder na concepção de Foucault presumem um enfrentamento permanente (MAIA, 1995). Isto implica que qualquer agrupamento humano estará sempre permeado por relações de poder, posto que a existência desse tipo de relação é coexistente à vida social.

Ainda segundo Foucault (1982), o poder é exercido somente sobre sujeitos livres e apenas enquanto são livres. Logo, “[...] escravidão não é uma relação de poder, pois o homem está acorrentado (neste caso fala-se de uma 
relação de constrangimento físico)." (FOUCAULT, 1982, p. 221). A liberdade é condição para exercício do poder, simultaneamente sua pré-condição, já que a liberdade precisa existir para o poder ser exercido. Do mesmo modo, embora a violência possa ser um instrumento utilizado nas relações de poder, ela não é um princípio básico da sua natureza. Lembrando que, na concepção foucaultiana, a atuação do poder ocorre muito mais sutilmente, não se restringindo apenas à aspectos negativos, tais como o uso de violência física.

A capacidade de recalcitrar, de se insurgir, de se rebelar e resistir são elementos constitutivos da própria definição de poder. Deste modo,

[...] a partir do momento em que há uma relação de poder, há uma possibilidade de resistência. Jamais somos aprisionados pelo poder: podemos sempre modificar sua dominação em condições determinadas e segundo uma estratégia precisa. (FOUCAULT, 2017, p. 241).

Em função disso, os procedimentos de poder sobre a vida são difusos, raramente formulados em discursos contínuos e sistemáticos (FOUCAULT, 1987). Eles são, a bem da verdade, uma instrumentalização multiforme, sendo impossível localizá-los em um tipo específico de instituição ou em um aparelho de Estado - embora tanto instituições específicas quanto aparelhos de Estado se utilizem deles. Foucault (1988) mostra que tal poder sobre a vida se desenvolveu a partir do século XVII em duas formas preponderantes: no adestramento do corpo para extrair o máximo possível de sua produtividade e na regulação das populações.

No cotidiano das organizações, a vigilância disciplinar não aparece de forma pura, muito embora as etapas do processo de compras de materiais de consumo levem à compreensão de parte das dinâmicas das relações de poder. Como já considerou Foucault (1972),

Onde há poder, ele se exerce. Ninguém é, propriamente falando, seu titular; e, no entanto, ele sempre se exerce em determinada direção, com uns de um lado e outros do outro; não se sabe ao certo quem o detém, mas se sabe quem não o possui. (FOUCAULT, 1972, p. 138). 
Ou seja, diante de um poder ao mesmo tempo visível e invisível, presente e oculto, questiona-se quem exerce o poder e onde o exerce, por meio de que revezamentos ou variações e quais instâncias de controle, de vigilância, de proibições, de coerções são acionadas. Classe dirigente, aparelho de Estado, é todo um conjunto de noções de análise.

De acordo com Foucault (1988), o poder deve ser entendido como o jogo de forças que, por meio de lutas e afrontamentos incessantes as transformam, reforçam, invertem. O poder ainda deve ser entendido como os "[...] apoios que tais correlações de força encontram umas nas outras, formando cadeias ou sistemas, ou, ao contrário, as defasagens e contradições que as isolam entre si.". (FOUCAULT, 1988, p. 89). Se imaginarmos que as relações de poder se fundam exclusivamente em um caráter negativo, torna-se difícil explicar o sucesso das inúmeras redes de dominação existentes nas sociedades e que vêm se perpetuando com certa facilidade. Talvez seja modificando nossa percepção do fenômeno do poder que possamos entender melhor essa dinâmica (MAIA, 1995).

O que faz com que o poder se mantenha e que seja aceito é simplesmente que ele não pesa só como a força que diz não, mas que de fato ele permeia, produz coisas, induz ao prazer, forma saber, produz discurso (FOUCAULT, 2017). Um importante aspecto nessa concepção de poder reside no fato do abandono de qualquer modelo centralizador.

Foucault (1987) apresenta o modelo compacto do dispositivo disciplinar como:

[...] o espaço fechado, recortado, vigiado em todos os seus pontos, onde os indivíduos estão inseridos num lugar fixo, onde os menores movimentos são controlados, onde os menores acontecimentos são registrados, onde um trabalho ininterrupto de escrita liga o centro e a periferia, onde o poder é exercido sem divisão, segundo uma figura hierárquica contínua, onde cada indivíduo é constantemente localizado, examinado e distribuído entre os vivos, os doentes e os mortos. (FOUCAULT, 1987, p.163).

$\mathrm{Na}$ disciplina cada um se define pelo lugar que ocupa na série, e pela distância que o separa dos outros. Para gerir a vida, Foucault (1987) destaca que 
os sistemas punitivos e de poder, em nossa sociedade, foram recolocados em uma economia política do corpo. O corpo, tanto individual quanto coletivo, passou a ser o principal alvo do poder.

O corpo está diretamente mergulhado num campo político; as relações de poder têm alcance imediato sobre ele; elas o investem, o marcam, o dirigem, o supliciam, sujeitam-no a trabalhos, obrigamno a cerimônias, exigem-lhes sinais. (FOUCAULT, 1987, p. 27).

A constituição do corpo como força de trabalho somente ocorre se ele está preso a um sistema de sujeição. Como destaca Foucault (1987), o corpo somente torna-se útil se é, concomitantemente, corpo produtivo e corpo submisso. A disciplina fabrica, desse modo, corpos submissos e exercitados, corpos dóceis. Se a exploração econômica separa a força e o produto do trabalho, "[...] a coerção disciplinar estabelece no corpo o elo coercitivo entre uma aptidão aumentada e uma dominação acentuada." (FOUCAULT, 1987, p. 119).

Inicialmente, Foucault (1987) observa como as disciplinas distribuem os indivíduos no espaço. Uma complexa arte de distribuir os trabalhadores e o trabalho sobre um quadro em que cada um ocupe um lugar: em cada lugar um indivíduo e cada indivíduo em seu lugar. Na divisão do processo de produção encontra-se a decomposição de forma individualizada da força de trabalho, o que ocorre também com o processo de compras de materiais de consumo analisado neste estudo. O espaço, de acordo com Foucault (1987), é quadriculado e as ligações devem ser ordenadas e delimitadas: cada operário devidamente posicionado na linha de montagem, cada tipo de doente em uma ala do hospital. Assim é mais fácil saber quem faltou, quem está atrasado, quem está melhor ou pior. Dessa maneira, o funcionário pode ser rapidamente reconhecido, o aluno encontrado, o doente medicado.

Todavia, o sucesso do poder disciplinar se deve, nas análises de Foucault (1987), ao uso de três instrumentos: a vigilância (exercida por meio do olhar hierárquico), a sanção normalizadora e sua combinação num procedimento que lhe é específico, o exame. De acordo com o autor, a vigilância tornou-se um decisivo operador econômico, na medida em que foi uma peça interna no 
aparelho de produção e uma engrenagem específica do poder disciplinar. Do ponto de vista foucaultiano, a vigilância torna o poder disciplinar um sistema integrado, que se organiza como um poder múltiplo, automático e anônimo, que repousa sobre os indivíduos e sobre seu funcionamento. "É o poder de uma rede de relações e olhares, de cima para baixo, concomitantemente, de baixo para cima e passa por ele por meio de efeitos que se apoiam uns sobre os outros." (SILVEIRA, 2005, p. 74) e que, nas palavras de Foucault (1987, p.148), “[...] gera fiscais perpetuamente fiscalizados.".

E se é verdade que sua organização piramidal lhe dá um chefe, de acordo com Silveira (2005), é o aparelho interno que produz poder e distribui os indivíduos nesse campo permanente e contínuo. É essa característica que permite ao poder disciplinar ser absolutamente indiscreto, pois está em toda a parte e sempre alerta, pois, em princípio, não deixa nenhuma parte às escuras e controla continuamente inclusive os que estão encarregados de controlar. E é absolutamente discreto, pois funciona permanentemente, em grande parte, em silêncio (SILVEIRA, 2005).

De acordo com Foucault (1987 apud SILVEIRA, 2005), o exame combina as técnicas da hierarquia que vigiam e as sanções que normalizam. É um recurso que tem por característica a elaboração de uma espécie de registro escrito dos resultados obtidos tanto com a vigilância hierárquica, quanto com a sanção normalizadora. O prontuário médico, o boletim da escola ou o diário de classe são exemplos.

O mais interessante do exame é que ele fez de cada pessoa um caso que, concomitantemente, é um objeto para o conhecimento e um alvo para o poder (FOUCAULT, 1987 apud SILVEIRA, 2005). Por outro lado, tem-se também um importante recurso de comparação que permite identificar os desvios entre os indivíduos. Como caso, a pessoa pode ser descrita, mensurada, medida e comparada a outras e a si própria, o que gera a noção da pessoa que deve ser treinada, retreinada, classificada, normalizada ou excluída. Assim, a sua descrição transforma-se em um método de controle. Podemos notar isso nos programas de avaliação de desempenho das empresas, nos boletins escolares 
(nota acima ou abaixo da média), no curso de graduação reconhecido e no curso não reconhecido, na nota do programa de pós-graduação.

\section{Procedimentos metodológicos}

O procedimento técnico de coleta dos dados iniciou-se com o mapeamento do processo de compras de materiais de consumo, que contou com a participação de servidores da universidade que atuavam diretamente na execução de determinadas tarefas. Foram entrevistados servidores dos seguintes setores: a) Almoxarifado; b) Setor de Compras, responsável por fazer o levantamento das necessidades de compras e por elaborar o Processo Administrativo para formalizar a solicitação; c) Departamento de Compras e Logística; d) Pró Reitor de Administração (PROAD).

As entrevistas semiestruturadas foram realizadas no período de 5 a 26 de abril de 2018, e as transcrições estenderam-se até o fim de abril. Os resultados foram analisados e interpretados por meio de duas perspectivas:

a) Disciplinar, mediante análise dos pressupostos de Foucault;

b) Documental, com ênfase no caráter social e material da informação, ideias sustentadas por Frohmann.

A teoria focaultiana mostra como todos os tipos de "informação" produzidos, disseminados e utilizados no processo de compras da universidade são regulados de acordo com procedimentos autorizados e regras de produção (sejam aquelas registradas nas rotinas ou outros modos de produção e reprodução documental) em circuitos padronizados e autorizados. Frohmann (2004), por sua vez, diz que Foucault mostra que as plataformas autorizadas de enunciação dependem de técnicas documentais específicas e institucionalizadas - uma Instrução Normativa publicada no Tribunal de Contas da União, por exemplo, tem autoridade de produção documental como legítimo local discursivo de enunciação. Isto é, a "informação”, fora dos domínios jurídicos no processo de compras públicas, não chama a atenção e não guia as práticas de ninguém, não tendo jurisdição. 


\section{$4 \mathrm{O}$ processo de compras de materiais de consumo}

Como se lê no Quadro 1, o processo de compras da universidade inicia-se com

a solicitação expressa do setor requisitante interessado, indicando sua necessidade.

Quadro 1 - Processo de compras de materiais de consumo.

\begin{tabular}{|l|l|}
\hline Etapas do processo & Setor responsável \\
\hline Solicitação da compra & Qualquer setor/ Solicitante \\
\hline $\begin{array}{l}\text { Conferência das } \\
\text { solicitações }\end{array}$ & Setor de Compras/ Solicitante \\
\hline $\begin{array}{l}\text { Elaboração do Termo de } \\
\text { Referência }\end{array}$ & Setor de Compras \\
\hline $\begin{array}{l}\text { Confeç̧ão do Mapa de } \\
\text { Preços }\end{array}$ & Setor de Compras \\
\hline Assinatura do responsável & Direção Administrativa \\
\hline Parecer jurídico & Procuradoria Jurídica \\
\hline Autorização da compra & $\begin{array}{l}\text { Pró-Reitoria de Administração (PROAD) encaminha à } \\
\text { Coordenação de Orçamento e Finanças (COF) para a verificação } \\
\text { da existência de recurso e se há limite para ser empenhado. Em } \\
\text { havendo dotação orçamentária, a COF faz a abertura da Nota de } \\
\text { Dotação e a PROAD autoriza a compra. Em não havendo, o } \\
\text { processo fica parado na PROAD aguardando a liberação de } \\
\text { rubrica. }\end{array}$ \\
\hline $\begin{array}{l}\text { Registro da compra no } \\
\text { certame }\end{array}$ & Departamento de Compras e Licitações \\
\hline $\begin{array}{l}\text { Elaboração e publicação } \\
\text { do edital de licitação de } \\
\text { compras }\end{array}$ & Departamento de Compras e Licitações \\
\hline $\begin{array}{l}\text { Realização da licitação } \\
\text { Homologação do resultado } \\
\text { da licitação }\end{array}$ & $\begin{array}{l}\text { Pregoeiro (o solicitante da compra pode acompanhar a realização e } \\
\text { dar suporte técnico para o Pregoeiro) }\end{array}$ \\
\hline $\begin{array}{l}\text { Elaboração das minutas } \\
\text { das notas de empenhos }\end{array}$ & Departamento de Compras e Logística de Administração \\
\hline $\begin{array}{l}\text { Confeção das notas de } \\
\text { empenhos }\end{array}$ & Gerência de Contabilidade e Finanças \\
\hline $\begin{array}{l}\text { Estabelecimento dos } \\
\text { prazos de entrega com o } \\
\text { fornecedor }\end{array}$ & Almoxarifado \\
\hline $\begin{array}{l}\text { Recebimento dos } \\
\text { materiais }\end{array}$ & $\begin{array}{l}\text { Almoxarifado (o solicitante da compra pode verificar se o material } \\
\text { recebido atende aos requisitos descritos no edital) }\end{array}$ \\
\hline $\begin{array}{l}\text { Registro no sistema do } \\
\text { almoxarifado central }\end{array}$ & Almoxarifado \\
\hline Pagamento ao fornecedor & Gerência de Contabilidade e Finanças \\
\hline
\end{tabular}

Tendo a solicitação analisada, passa-se à elaboração do Termo de Referência e do Mapa de Preços, etapas que precedem e dão subsídios à elaboração do Edital. Tais ações requerem estimativa do valor da compra, 
mediante comprovada pesquisa de preços, para justificar a projeção inicial do preço da aquisição. A Lei n. 8.666/93 faz remissões à estimativa de custos como baliza procedimental necessária nas licitações públicas. O parágrafo $2^{\circ}$ do artigo 40 da referida lei determina a necessidade de orçamento estimado em planilhas de quantitativos e preços unitários como anexo do edital. O artigo 44 da mesma lei trata sobre o julgamento das propostas e exige que o órgão licitante possua estimativa prévia que permita verificar se os preços propostos são realizáveis, exequíveis ou compatíveis com os preços praticados pelo mercado.

Em seguida, há a aprovação da autoridade competente (neste estudo, é o Diretor Administrativo) e o início da protocolização e da numeração do processo licitatório no sistema informatizado denominado Sig@ Processos.

Paralelamente, ocorre a publicação da licitação e do edital. Nesse último, constam as regras e condições para a realização do certame, além do local onde se reunirão os interessados em participar, quando se tratar de licitação. Após identificada a modalidade licitatória (neste exemplo, é o Pregão), cabe definir o critério de julgamento, que na quase totalidade das vezes é o Menor Preço. No caso da modalidade Pregão, o licitante vencedor é aquele que apresentar a proposta de acordo com as especificações do edital e ofertar o menor preço.

A próxima etapa é a entrega das propostas. Inicialmente, cada proposta é checada; aquelas que não estiverem de acordo com as condições préestabelecidas no edital são desclassificadas. O certame ocorre em sessão única, tendo o pregoeiro como autoridade. Trata-se de uma sessão pública, portanto, é permitido que qualquer interessado possa dela participar, porém na qualidade de ouvinte.

Dando seguimento, as propostas são classificadas em ordem crescente de preços. No decorrer da sessão, o licitante que ofertou a proposta de menor valor seguirá no certame oferecendo novos lances verbais, até que não haja mais lances para cobrir a proposta de menor preço.

Finalizada a fase das propostas, o pregoeiro verifica a habilitação do vencedor. Caso ele não esteja habilitado, isto é, sua documentação não está de acordo com as exigências do edital, o pregoeiro passa a analisar a documentação do segundo colocado, e assim sucessivamente. 
Não havendo recursos, passa-se para a fase de adjudicação, momento em que o pregoeiro informa o licitante vencedor. Em seguida, a autoridade superior da universidade (nesse caso, o Pró-Reitor de Administração) faz a homologação da licitação e convoca o vencedor para celebrar a assinatura do contrato.

\subsection{O poder disciplinar nos processos de compras públicas}

Como exposto, o processo de compras é regido por legislação (Quadro 2) que normatiza todo o trâmite. Já na solicitação da compra, a especificação adequada do produto reveste-se de importância na realização de uma aquisição vantajosa para a administração pública. Incomum, pois em toda e qualquer relação de negócio, seja em esfera privada ou pública, sempre se busca a proposta mais vantajosa.

Quadro 2 - Principais dispositivos legais que regem o processo de compras de materiais de consumo de uma universidade pública federal

Lei ${ }^{\circ}$ 4.150, de 1962, quanto aos requisitos da Associação Brasileira de Normas Técnicas (ABNT). Lei 8. 666, de 21 de junho de 1993 - Institui normas para licitações e contratos. Lei no 8.078, de 1990 Código de Defesa do Consumidor. Lei no 9.784, de 1999 Regula o processo.

Lei $\mathrm{n}^{0} \mathbf{1 0 . 5 2 0}$, de 17 de julho de 2002 - Institui modalidade de licitação denominada pregão.

Lei complementar $n^{\circ} 123$ de 14 de dezembro de 2006 Institui o Estatuto Nacional da Microempresa e da Empresa de Pequeno Porte.
Cronograma de solicitações de compras - estabelecido pelo setor de compras

Edital

Decreto Federal $\mathrm{n}^{\circ} \mathbf{3 . 5 5 5}$ de 8 de agosto de 2000 - Aprova o Regulamento para a modalidade de licitação denominada pregão. Decreto $n^{0}$ 5.450, de 31 de maio de 2005 - Regulamenta o pregão, na forma eletrônica.

Decreto $n^{0} 8.538$, de 6 de outubro de 2015 - Regulamenta o tratamento favorecido, diferenciado e simplificado para as microempresas, empresas de pequeno porte, agricultores familiares, produtores rurais pessoa física, microempreendedores individuais e sociedades cooperativas de consumo nas contratações públicas de bens, serviços e obras no âmbito da administração pública federal.
Instrução Normativa $n^{0}$ 3, de 26 de abril de 2018. Estabelece regras de funcionamento do SICAF.

Instrução Normativa SLTI/MP no 1 DE 26/03/2014 - Altera a Instrução Normativa $n^{\circ} 3$, de 16 de dezembro de 2011, que estabelece procedimentos para a operacionalização do pregão, na forma eletrônica.

Instrução Normativa $\mathbf{n}^{\circ} 03$, de 20 de abril de 2017 - Altera a Instrução Normativa $\mathrm{n}^{\circ} 5$, de 27 de junho de 2014, que dispõe sobre os procedimentos administrativos básicos para a realização de pesquisa de preços.

Fonte: Elaborado pelos autores com base nos dados da pesquisa (2019).

Ocorre que, na Administração Pública, isso se trata de uma obrigação.

Os órgãos de governo têm o dever legal, que os obriga, exceto para alguns raros 
casos, a promover um procedimento prévio para as contratações públicas, que se denomina Licitação (COSTA, 2017). Por seu turno, a obrigatoriedade de licitar encontra seu imperativo legal no art. 37 da Constituição Federal de 1988, regulamentado pela Lei 8.666, de 21 de junho de 1993, que disciplina as licitações e contratos da Administração Pública.

Esse é o corolário do princípio das instituições de disciplina que Foucault (1987) entendia como uma prática social, que subordina a atividade administrativa à lei. Todavia, de acordo com Motta (2010), essa tarefa, que inicialmente pode parecer simples, de fato não é. Segundo o autor, construir especificações de qualidade e eficiência de um produto depende de um pessoal bem capacitado para tal, o que é um fator de dificuldade na administração federal brasileira, dada a escassez de treinamento dos recursos humanos.

Ademais, as aquisições de materiais de consumo por meio da modalidade licitatória Pregão podem, em muitos casos, não conduzir o certame à proposta mais vantajosa para o órgão licitante. Sob uma dimensão econômica, a proposta mais vantajosa pode conduzir a uma avaliação sob a perspectiva da eficiência, e levar em consideração o menor preço.

Motta (2010, p. 94) concluiu que “[...] as aquisições públicas federais brasileiras não estão calcadas no resultado, mas no cumprimento estrito do rito legal.”. Na prática, de acordo com o autor, qualquer outra dimensão além do cumprimento do rito legal que se queira perseguir em termos de melhora da qualidade das aquisições torna-se irrelevante.

O poder disciplinar aplica-se a fim de normalizar, a partir de uma definição de um comportamento desejável a priori. Com essa definição do normal a ser realizado, os mecanismos disciplinares procuram fazer com que as pessoas o assumam. Efetivamente, o responsável pelo setor de compras e os demais servidores da universidade seguem os Modelos de Licitações e Contratos de Edital, Termo de Referência, Mapa de Registro de Preços e Termo Contratual. Alguns modelos são disponibilizados no site da Advocacia Geral da União (AGU, 2019) e servem como ponto de partida para a confecção de minutas de editais e anexos, ao mesmo tempo em que contêm referências que orientam a manter a regularidade dos textos finais, a fim de conferir segurança e 
celeridade da análise jurídica. Para correta utilização dos modelos, a AGU orienta a leitura das notas explicativas constantes dos documentos. A responsabilidade desses servidores toma vulto e evidência na Lei 8.666 de 1993, no seu art. 14: “[...] nenhuma compra será feita sem a adequada caracterização de seu objeto e indicação dos recursos orçamentários para seu pagamento, sob pena de nulidade do ato e responsabilidade de quem lhe tiver dado causa.".

A licitação constitui-se como o mais puro mecanismo de disciplina e padronização, obrigatório para as contratações de todas as entidades mantidas com recursos públicos, evidenciando mais uma vez as regras do direito que delimitam formalmente o poder. São exceções os processos de licitação, como as dispensas e as inexigibilidades, ambas também regidas por regras e especificidades definidas na Lei de Licitações.

Mas a elevação do controle na esfera das licitações ocorreu com a inserção do Pregão ao sistema de compras. Conforme a Lei de Licitações, quando uma instituição pública precisa contratar determinados serviços, necessita, primeiramente, habilitar os concorrentes, para depois abrir a proposta de preço. No Pregão, primeiro discute-se o preço, depois a habilitação. Na modalidade de Licitação, o Pregão foi instituído em todos os âmbitos da federação pela Lei Federal no 10.520, de 17 de julho de 2002. A realização do Pregão, conforme Decreto ${ }^{\circ}$ 5.450, de 31 de maio de 2005, na forma eletrônica, mantém a disputa por meio de lances, em sessões públicas via Internet, processado por meios do Portal governamental - Compras Governamentais.

O Sistema de Registro de Preços é um cadastro de produtos e de fornecedores para compras sucessivas. Esse cadastro se faz por intermédio de um processo licitatório e, sempre que necessitar de um produto ou serviço, a Administração Pública deve recorrer ao referido cadastro.

O Termo de Referência, de acordo com a Lei 8.666/93, consiste em um documento que indica o objeto de forma precisa, suficiente e clara, vedadas especificações que, por excessivas, irrelevantes ou desnecessárias, limitem ou frustrem a competição ou sua realização. O Mapa de Preços consiste em uma planilha com a descrição dos itens contendo três orçamentos advindos de uma pesquisa de preço, de onde será obtida a média aritmética simples, que servirá 
de referência para o pregoeiro lançar no certame e permitir a negociação com o fornecedor.

O Edital consiste em um ato convocatório que tem por finalidade fixar as condições necessárias à participação dos licitantes, ao desenvolvimento da licitação e à futura contratação, além de estabelecer um elo entre a Administração Pública e os licitantes. As aquisições públicas federais brasileiras, procedidas mediante licitação, são realizadas por uma Comissão de Licitação ou por um Pregoeiro, ambos, necessariamente designados por autoridade competente. Quando utilizada a modalidade Pregão, o pregoeiro tem a função de auxiliar no recebimento das propostas e no exame dos documentos entregues pelos licitantes, bem como no exame da habilitação.

Para além dos órgãos de fiscalização e controle, são os servidores públicos que efetivam as demandas, definem e descrevem a qualidade do objeto, dimensionam as quantidades, procedem à análise das amostras e têm por função fiscalizar o recebimento dos materiais adquiridos. Sem excluir de tal apreciação, obviamente, a atuação da autoridade competente que homologa o julgamento das propostas.

Contudo, para Foucault (1988), a análise em termos de poder não deve postular, como dados iniciais, a soberania do Estado, a forma da lei ou a unidade de uma dominação: "essas são apenas, e antes de tudo, suas formas terminais" (FOUCAULT, 1988, p. 88). Sendo assim, para compreender o poder nos processos de compras públicas devemos primeiramente entender o poder:

[...] como a multiplicidade das correlações de força imanente ao domínio em que se exercem e constitutivas de sua organização; o jogo que, por meio de lutas e afrontamentos incessantes as transforma, reforça, inverte; os apoios que tais correlações de força encontram umas nas outras, formando cadeias ou sistemas ou ao contrário, as defasagens e contradições que as isolam entre si. (FOUCAULT, 1988, p. 88-89).

Motta (2010) e Silveira (2005) indicam fatores institucionais e contingências históricas que devem ser levados em conta para mostrar como os dispositivos legais tornam-se informativos. Combinada com o princípio jurídico da legalidade, a legislação brasileira em vigor relacionada às compras 
governamentais tem como preocupação primordial com o combate à corrupção. Princípio que torna nulo o ato que não siga exatamente o que está definido na lei, propiciando que qualquer equívoco, omissão ou erro, independentemente de sua importância para o desfecho final, seja o suficiente para a anulação de todo o procedimento e eventual punição de quem lhe deu causa.

Não bastasse à legislação brasileira de licitações ser tomada por uma forte preocupação com o combate a corrupção, o poder nas instituições públicas, funcionando como guardião da Justiça, tem ainda seus mecanismos de controle, “[...] os órgãos públicos são regularmente fiscalizados pelos Tribunais de Contas, que verificam o cumprimento das regras estabelecidas aos contratos de compras." (SILVEIRA; CAMARGO, 2006, p. 3), entre os principais: Advocacia Geral da União (AGU) e Tribunal de Contas da União (TCU), Ministério da Transparência e Controladoria Geral da União (CGU).

Por conseguinte, apesar de os legisladores da Lei 8.666/93 explicitarem que a licitação deveria, além de garantir a isonomia entre os concorrentes, selecionar a proposta mais vantajosa para a Administração Pública, "o elenco de princípios citados na lei como base inescapável para o julgamento de qualquer proposta, remete à supremacia do princípio da isonomia sobre o recém incorporado princípio constitucional da eficiência." (MOTTA, 2010, p. 116). Os servidores públicos naturalmente priorizam a legalidade e a isonomia, em detrimento de quaisquer outros princípios, tais como o da razoabilidade ou da eficiência. Como observou Motta (2010, p. 116),

[...] a combinação e a interpretação rígida desses princípios têm levado à formação e à consolidação de uma cultura de punição severa de qualquer descumprimento ritualístico, não existindo o mesmo rigor em relação ao resultado alcançado.

Mas não basta só cumprir a lei, tem-se que cumpri-la e comprar bem. Por isso, de acordo com Motta (2010), quando o assunto é o critério de tomada de decisão de quem vence um processo de licitação, parece que os órgãos de controle ainda não conseguiram valorizar tanto a eficiência quanto a eficácia. $\mathrm{E}$ nisso deve mudar de foco de "menor valor" para "melhor valor", ponderando outros critérios como qualidade dos serviços ou produtos a serem adquiridos, 
pondera Motta (2010). Isso, de acordo com o autor, não significa desperdiçar o dinheiro público, e sim evitar a compra de um produto ruim, desperdiçando dinheiro do contribuinte.

\subsection{Os documentos como propriedades materiais e institucionais da informação}

Frohmann (2004) associa a informatividade de um documento às práticas que envolvem o documento. Como se lê no Quadro 2, temos um conjunto de documentos no centro do processo de compras públicas. Os servidores públicos que executam o processo de compras que se comportam de forma desviante passam a ser objeto das sanções com objetivo de normalização, como previsto na Lei 8.666/93, no seu art. 14. Essa espécie de combinação entre vigilância hierárquica e sanção normalizadora tem efeitos sobre o exame disciplinar. $\mathrm{O}$ exame que coloca os indivíduos num campo de vigilância situa-os igualmente numa rede de registros, compromete-os em toda um conjunto de documentos que os captam e os fixam (FROHMANN, 2008). Os procedimentos de exame são acompanhados concomitantemente de um sistema de registro intenso e de acumulação de documentos. Um poder de escrita é constituído como uma peça essencial nas engrenagens da disciplina (FOUCAULT, 1987). No processo de compras públicas toma destaque o sistema de registro para documentar cada etapa do processo para que os órgãos de fiscalização e controle possam, por sua vez, fazer sua verificação. Embora, como já evidenciou Silva, “[...] a quantidade de papel que é envolvida num procedimento licitatório frustra qualquer tentativa séria de exercer o controle. E a corrupção somente é descoberta quando há denúnciall." (SILVA, 2004, p. 119).

Mas a disciplina se vale da vigilância como um de seus mecanismos mais eficazes. O processo que Foucault (1987) chama de escrita disciplinar coloca indivíduos num campo de vigilância mediante a inserção de registros sobre eles em circuitos institucionais altamente rotinizados. Nas compras públicas, os órgãos reguladores e fiscalizadores se traduzem nas formas de vigilância visível, pois tratam de investigar, em nome do poder, as reais práticas exercidas pelos servidores públicos. Em cada documento produzido consta uma 
assinatura de um dos servidores. Essa assinatura os responsabiliza por qualquer falha detectada. Nesse caso, o processo de compras públicas relaciona-se com aquilo que podemos chamar de objeto e mostra como o poder está investido em práticas reais, aparentes e efetivas, e documentadas.

A preocupação de Frohmann $(2001 ; 2004 ; 2008)$ com os aspectos sociais e materiais da informação convida a uma análise foucaultiana das propriedades materiais e institucionais da informação no processo de compras públicas. Frohmann (2004) orienta perseguir as variações ou contingências históricas das muitas forças sociais e políticas que configuram as práticas documentárias. Em outras palavras, de acordo com Frohmann (2004, p. 405), “[...] o gênio está fora da garrafa.": a informatividade dos documentos, quando reconhecida como dependente das práticas, depende também daquilo que molda os documentos e os configura.

No Brasil, muito do controle sobre o serviços público foi difundido nos anos de 1990, com a nova gestão pública, reconhecida "enquanto uma multiplicidade de práticas em busca da ampliação da eficiência, eficácia e efetividade nas ações do setor público.” (MAGALHÃES; COELHO, 2018, p. 350). No governo de Fernando Henrique Cardoso, a criação do Plano de Reforma do Estado em 1995, tinha como objetivo, segundo Cunha (2015), promover uma administração pautada na redução da máquina do Estado, principalmente em termos de pessoal. A Lei $\mathrm{n}^{\circ}$ 9.632/98 solidificou essa política pública, quando editou a extinção de cargos no âmbito da administração pública federal direta, autárquica e fundacional.

Sobre a reforma do Estado faz-se necessário considerar que a mesma não se tratou apenas de uma reforma administrativa, tratou-se também de uma luta ideológica empreendida por sofisticados ideólogos que tinham o desafio de introduzir o ethos privado do mercado na esfera das funções públicas, e, além disso, controlar o serviço público por meio de técnicas racionais, muito bem aceitas no mercado.

Foucault (1987) utilizou o termo "panóptico" para retratar a sociedade disciplinar. A instalação progressiva de um sistema de controle pode ser verificada nos dispositivos legais por vezes naturalizados, a ponto de não serem 
facilmente percebidos pelos servidores, criados ao longo dos anos sobre o processo de compras públicas.

Entretanto, de acordo com Foucault (1988), essa representação disciplinar do poder não dá conta da dinâmica de como ele se exerce de fato. $\mathrm{O}$ autor compreende o poder como um conjunto de correlações de forças que se auto constituem, produzem e organizam os domínios em que estão presentes e inseridas. Em licitações envolvendo compras de materiais de consumo, existem atores distintos com atribuições bem definidas e segregadas no processo. Nessas circunstâncias, há a dispersão do poder, uma vez que cada tarefa precedente desempenhada por determinado servidor público seja verificada por outro servidor, encarregado da execução da fase ou tarefa posterior. Tal sistemática e procedimento desembocam num ciclo virtuoso de fiscalização e controle administrativo nas ações praticadas.

Quando o ato subsequente à tarefa ora realizada é verificado por outro servidor público distinto daquele que a realizou, tal conduta engendra uma contínua vigilância e uma permanente disciplina nas atribuições inerentes às compras públicas, de forma a minimizar a possibilidade de desvios e fraudes. $\mathrm{O}$ que caracteriza o poder que estamos analisando na concepção de Foucault (1982) é que traz à ação relações entre indivíduos (ou entre grupos). "Para não nos deixar enganar; só podemos falar de estruturas ou de mecanismo de poder na medida em que supomos que certas pessoas exercem poder sobre outras." (FOUCAULT, 1982, p. 217). Ao separar todos os eventos sequenciais que precedem os processos de compras públicas, cria-se um ambiente conveniente de vigilância no qual as tarefas executadas por um servidor público são subsequentemente acompanhadas e fiscalizadas por outro, na perspectiva de inibir condutas ilícitas e restringir os riscos de erros ou omissões.

Embora seções ou setores diferentes, compostos por servidores distintos, tenham a incumbência de, separadamente, definir o objeto e preencher a requisição, estimar o preço de mercado, elaborar o edital de licitação, conduzir o certame, empenhar, liquidar (atestar) e receber o objeto licitado, ainda é o próreitor quem detém o controle sobre as decisões orçamentárias. Cabe a ele decidir a liberação ou não da rubrica para a solicitação do pedido de compras. É o pró- 
reitor de administração que autoriza a compra e homologa o resultado da licitação. Portanto, embora o processo respeite o princípio da segregação de funções que deve perpassar por todo o rito de execução das despesas públicas, a administração central (Reitoria) detém o controle de considerável parte dos recursos, fixando as prioridades para a sua aplicação.

Ademais, uma vez que a lei de licitações exige que mude a composição dos membros da comissão de licitação, as organizações públicas não formam quadros de recursos humanos, não criam expertise. Os servidores públicos trabalham praticamente obrigados na área de compras. A área é laboriosa, vulnerável, difícil e não reconhecida, seja porque tem aqueles que reclamam porque não se comprou o que queriam, seja pelos órgãos de controle, como a controladoria geral e o tribunal de contas, pela vigilância. Nessas condições de pressão e falta de reconhecimento, não são todos que querem assumir essas atribuições.

O conjunto dos dispositivos legais (leis, decretos, instruções normativas) e o consequente aumento de formalismo, por meio de maior especificação de tudo que é realizado, transformam as compras públicas em uma burocracia atenta aos meios e não aos fins. Cria-se uma narrativa que desqualifica a imagem do servidor público, responsabilizando-o pela lentidão dos procedimentos. Ou seja, o tempo entre a detecção da necessidade e a disponibilidade do bem ou serviço demandado oculta as relações de poder que se estabelecem no processo de compras públicas e a sociedade acusa os servidores públicos de ineficientes a ponto de aceitar os discursos de verdade por ela produzidos.

A ideia de materialidade de um enunciado implica, por si só, a capacidade de gerar e difundir narrativas, algo que adquire vida própria com o uso, em associação com o contexto em que são enunciadas. Mas a base da materialidade de um enunciado, para Foucault (1972), é a instituição. Ou seja, a materialidade do enunciado pode ser analisada pelo grau de sua imersão institucional: as rotinas institucionalizadas estabelecem e mantêm as relações entre enunciados, dando a eles peso, massa, inércia e resistência. Assim, de acordo com o autor, a materialidade de um enunciado entra em várias redes e 
diversos campos de uso, é integrada a operações e estratégias em que sua identidade é mantida ou apagada, servindo ou resistindo a vários interesses e participando de desafios e lutas.

Um exemplo em um nível correspondentemente alto de significância sobre as práticas institucionais é o trabalho de Foucault (1988) relativo à concepção jurídico-discursiva, centrado na enunciação da lei. O modo jurídicodiscursivo é proveniente das grandes instituições, tais como o Estado e a Igreja que se desenvolveram na Idade Média. $\mathrm{O}$ poder se formulava na legislação personificada nessas instituições e, por isso, o direito constituiu o modo de manifestação e de aceitabilidade desse poder.

\section{Considerações finais}

Este artigo contribuiu com os estudos da materialização documentária da informação ao tempo que em que se analisou as relações de poder que se configuram nos mecanismos de disciplinarização e de regulação que orientam a execução do processo de compra das universidades públicas federais em geral.

No campo da Ciência da Informação, apontou que, uma vez que os documentos adquirem materialidade, a atenção muda de acordo com as instituições que regulam sua produção e circulação e os tipos de arranjos sociais que contribuem para a sua estabilidade ao longo do tempo.

A análise do poder disciplinar evidenciou como as práticas sociais e institucionalizadas com um conjunto de documentos produzem um arcabouço conceitual promissor para pensar filosoficamente sobre informação. A razão para essa conclusão é de que a atenção às práticas e aos documentos - nos quais entendemos editais, mapa de preços e a grande variedade de registros que circulam em uma miríade de formatos no processo de compras públicas - revela como documentos específicos, em determinados momentos e lugares e em áreas específicas do terreno institucional, social e cultural, tornam-se informativos materializados e se conformam como mecanismos disciplinares.

As conclusões deste trabalho apontam que as raízes documentais e institucionais dos dispositivos legais que regem o processo de compras públicas das universidades respondem por sua força e autoridade. A análise do poder 
disciplinar foucaultiano compreende a materialidade da informação como um conjunto de enunciados legais alcança estabilidade suficiente para constituir conhecimento legítimo e autorizado de pessoas e processos.

O foco predominante de atuação do processo de compras públicas é a formalização dos procedimentos, sem atenção aos resultados. O objetivo é o cumprimento estrito do rito legal: a melhor compra é o menor preço e a maior transparência de cada ação executada, mas, principalmente, é ter as contas aprovadas, porque a lógica está toda em evitar irregularidades.

A legislação e a normatização do processo criam um sistema de controle e vigilância, estimulando a fiscalização constante de uns servidores públicos sobre os outros em cada etapa de desenvolvimento das compras, além de submetê-los a forte pressão dos escalões superiores. Esses quadros de servidores públicos, pouco treinados, alguns desmotivados e na sua maioria pressionados pela rigidez da legislação, são os responsáveis por bilhões de reais em compras todos os anos. Mas tal situação assume contornos mais graves quando contrastada com os órgãos de fiscalização e controle externo, cujos servidores possuem sua carreira própria, seus concursos específicos, remuneração adequada e valorização da carreira.

Somada a sua situação excessivamente burocrática, o aparato disciplinar de combate à corrupção prevalece de modo quase dominante, parametrizando todas as fases do processo de compras e, como em uma mesma formação discursiva, apontando o servidor público como candidato à corrupção. A Administração Pública é considerada irresponsável e gastadora — portanto, geradora de custos. Assim, a disciplina dos órgãos reguladores impõe aos servidores (ditos irresponsáveis) a adoção de políticas, regras e normas "sólidas" e "corretas". Servidores públicos são julgados e condenados ou absolvidos pelas ações de auditoria dos órgãos fiscalizadores (dito racionais).

Ademais, o que agrava a situação é que, no limiar do discurso do processo de compras públicas, o serviço público é reputado como lento, burocrático e ineficiente, como se isso dependesse exclusivamente de habilidades em eficiência e eficácia de quem executa o serviço. Essas associações, em movimento, caracterizam o próprio discurso como prática. 

universidades públicas: contribuição para os estudos dos documentos e da materialidade da informação Nadi Helena Presser, Nadja Macêdo de Araújo e Juliene da Silva Barros Gomes

\section{Referências}

ADVOCACIA GERAL DA UNIÃO (AGU). Modelos de licitações e contratos. Comissão Permanente de Licitações e Contratos Administrativos, 2019. Disponível em:

http://www.agu.gov.br/page/content/detail/id_conteudo/270265. Acesso em: 10 de jul. 2019.

ARAUJO, Nadja. Macedo de. As relações de poder que se configuram na execução dos processos de compras: o caso da Unidade Acadêmica de Garanhuns e os demais agentes da Universidade Federal Rural de Pernambuco. 2018. 109 folhas: il. $30 \mathrm{~cm}$. Dissertação (Mestrado em Gestão Pública), Centro de Ciências Sociais Aplicadas, Universidade Federal de Pernambuco, 2018.

BRASIL. Presidência da República. Lei 8.666 de 21 de junho de 1993. Lei de Licitações e Contratos. Regulamenta o artigo 37, inciso XXI, da Constituição Federal, institui normas para licitações e contratos da Administração Pública e dá outras providências. Diário Oficial da União, Brasília, DF, 22 jun. 1993 e republicada Diário Oficial [da] República Federativa do Brasil, Brasília, DF, 6 jul. 1994. Disponível em:

http://www.planalto.gov.br/ccivil_03/leis/18666cons.htm. Acesso em: 15 jul. 2018.

BRASIL. Presidência da República. Lei n ${ }^{\circ} 4.150$ de 21 de novembro de 1962. Institui o regime obrigatório de preparo e observância das normas técnicas nos contratos de obras e compras do serviço público de execução direta, concedida, autárquica ou de economia mista, através da Associação Brasileira de Normas Técnicas e dá outras providências. Diário Oficial da União, Brasília, 11 jan. 1963. Disponível em: http://www.planalto.gov.br/ccivil_03/leis/19501969/L4150.htm. Acesso em: 09 jul. 2018.

BRASIL. Presidência da República. Lei nº 9.632 de 07 de maio de 1998. Dispõe sobre a extinção de cargos no âmbito da Administração Pública Federal direta, autárquica e fundacional, e dá outras providências. Brasília, Diário Oficial da União, Brasília, 08 maio 1998. Disponível em: http://www.planalto.gov.br/ccivil_03/LEIS/L9632.htm. Acesso em: 20 jan. 2019.

BRASIL. Presidência da República. Lei n 9.784 de 29 de janeiro de 1999. Regula o processo administrativo no âmbito da Administração Pública Federal. Brasília, Diário Oficial da União, Brasília, 01 fev. 1999. Disponível em: http://www.planalto.gov.br/ccivil_03/leis/19784.htm Acesso em: 25 jan. 2019.

BRASIL. Presidência da República. Lei no 10.520 de 17 de julho de 2002. Institui, no âmbito da União, Estados, Distrito Federal e Municípios, nos termos do art. 37, inciso XXI, da Constituição Federal, modalidade de licitação denominada pregão, para aquisição de bens e serviços comuns, e dá outras 
providências. Diário Oficial da União, Brasília, 18 jul. 2002. Disponível em: http://www.planalto.gov.br/ccivil_03/leis/2002/110520.htm Acesso em: 28 jan. 2019.

BRASIL. Presidência da República. Lei complementar no 123 de 14 de dezembro de 2006. Institui o Estatuto Nacional da Microempresa e da Empresa de Pequeno Porte. Diário Oficial da União, Brasília, 15 dez. 2006. Disponível em: http://www.planalto.gov.br/ccivil_03/leis/lcp/lcp123.htm. Acesso em: 5 mar. 2018.

BRASIL. Presidência da República. Lei no 12.305 de 02 de agosto de 2010. Institui a Política Nacional de Resíduos Sólidos; altera a Lei n⿳ํㅜ 9.605, de 12 de fevereiro de 1998; e dá outras providências. Diário Oficial da União, Brasília, 03 ago. 2010. Disponível em: http://www.planalto.gov.br/ccivil_03/_ato20072010/2010/lei/112305.htm. Acesso em: 18 set. 2018.

BRASIL. Presidência da República. Lei complementar $n^{\circ}$ 147, de 7 de agosto de 2014. Altera a Lei Complementar no 123, de 14 de dezembro de 2006, e as Leis nos 5.889, de 8 de junho de 1973, 11.101, de 9 de fevereiro de 2005, 9.099, de 26 de setembro de 1995, 11.598, de 3 de dezembro de 2007, 8.934, de 18 de novembro de 1994, 10.406, de 10 de janeiro de 2002, e 8.666, de 21 de junho de 1993; e dá outras providências. Diário Oficial da União, Brasília, 8 ago. 2014. Disponível: http://www.planalto.gov.br/ccivil_03/leis/LCP/Lcp147.htm. Acesso em: 23 set. 2018.

BRASIL. Presidência da República. Decreto Federal no 3.555 de 8 de agosto de 2000. Aprova o Regulamento para a modalidade de licitação denominada pregão, para aquisição de bens e serviços comuns. Diário Oficial da União, Brasília, 09 ago. 2000. Disponível em: http://www.planalto.gov.br/ccivil_03/decreto/D3555.htm. Acesso em: 18 set. 2018.

BRASIL. Presidência da República. Decreto no 5.450, de 31 de maio de 2005. Regulamenta o pregão, na forma eletrônica, para aquisição de bens e serviços comuns, e dá outras providências. Diário Oficial da União, Brasília, 01 jun. 2006. Disponível em: http://www.planalto.gov.br/ccivil_03/_Ato20042006/2005/Decreto/D5450.htm. Acesso em: 18 set. 2018.

BRASIL. Presidência da República. Decreto n⿳0 8.538, de 6 de outubro de 2015. Regulamenta o tratamento favorecido, diferenciado e simplificado para as microempresas, empresas de pequeno porte, agricultores familiares, produtores rurais pessoa física, microempreendedores individuais e sociedades cooperativas de consumo nas contratações públicas de bens, serviços e obras no âmbito da administração pública federal. Diário Oficial da União, Brasília, 07 out. 2015. Disponível em: http://www.planalto.gov.br/ccivil_03/_Ato2015-

2018/2015/Decreto/D8538.htm. Acesso em: 18 set. 2018. 

universidades públicas: contribuição para os estudos dos documentos e da materialidade da informação Nadi Helena Presser, Nadja Macêdo de Araújo e Juliene da Silva Barros Gomes

BRASIL. Presidência da República. Instrução Normativa no 3, de 26 de abril de 2018. Estabelece regras de funcionamento do Sistema de Cadastramento Unificado de Fornecedores (Sicaf), no âmbito do Poder Executivo Federal. Disponível em:

https://www.comprasgovernamentais.gov.br/index.php/legislacao/instrucoesnormativas/406-instrucao-normativa-n-02-de-11-de-outubro-de-2010. Acesso em: 05 ago. 2018.

BRASIL. Presidência da República. Instrução Normativa SLTI/MP no 01/2010. Dispõe sobre os critérios de sustentabilidade ambiental na aquisição de bens, contratação de serviços ou obras pela Administração Pública Federal direta, autárquica e fundacional e dá outras providências. Disponível em: https://www.comprasgovernamentais.gov.br/index.php/legislacao/instrucoesnormativas/407-instrucao-normativa-n-01-de-19-de-janeiro-de-2010. Acesso em: 8 jun. 2018.

BRASIL. Presidência da República. Instrução Normativa $\mathbf{n}^{\mathbf{0}} \mathbf{1}$, de 26 de março de 2014. Altera a Instrução Normativa nº 3, de 16 de dezembro de 2011, que estabelece procedimentos para a operacionalização do pregão, na forma eletrônica. Disponível em:

https://www.comprasgovernamentais.gov.br/index.php/legislacao/instrucoesnormativas/387-instrucao-normativa-n-1-de-26-de-marco-de-2014. Acesso em: 08 jul. 2018.

COSTA, Alexandre. A proposta mais vantajosa para a Administração Pública na modalidade de licitação pregão. [S.l.]: JUS.com.br., julho, 2017. Disponível em: https://jus.com.br/artigos/59464/a-proposta-mais-vantajosapara-a-administracao-publica-na-modalidade-de-licitacao-pregao. Acesso em: 12 ago. 2019.

CUNHA, Yuri Rodrigues da. Terceirização e terceirizados: um estudo sobre os impactos objetivos e subjetivos da terceirização nos trabalhadores terceirizados que atuam no setor de limpeza de Escolas Estaduais no Município de Marília-SP. 2015. Dissertação (Mestrado em Ciências Sociais) - Faculdade de Filosofia e Ciências, Universidade Estadual Paulista, Marília, 2015.

FOUCAULT, Michel. The archaeology of knowledge and the discourse on language. Pantheon Books: New York, 1972. 245 p.

FOUCAULT, Michel. The Subject and Power. In: DREYFUSS, Hubert L.; RABINOW, Paul. Michel Foucault: beyond structuralism and hermeneutics. 2a ed., Chicago: The University Chicago Press, 1982. p. 208 - 226.

FOUCAULT, Michel. Vigiar e punir: nascimento da prisão. 20. Petrópolis: Vozes, 1987. 296 p.

FOUCAULT, Michel. História da sexualidade: a vontade de saber. 13. ed. Rio de Janeiro: Graal, 1988. 125 p. 

universidades públicas: contribuição para os estudos dos documentos e da materialidade da informação Nadi Helena Presser, Nadja Macêdo de Araújo e Juliene da Silva Barros Gomes

FOUCAULT, Michel. Microfísica do poder. Roberto Machado (Org). $6^{\mathrm{a}}$ ed., Rio de Janeiro: Paz e Terra, 2017. 432 p.

FROHMANN, Bernd. Discourse and documentation: Some implications for pedagogy and research. Journal of Education for Library and Information Science, State College, Pa., v. 42, n. 1, p. 12-26, 2001.

FROHMANN, Bernd. Documentation redux: prolegomenon to (another) Philosophy of Information. Library Trends, Champaign, Ill., v. 52, n. 3, p. 387-407, 2004.

FROHMANN, Bernd. O caráter social, material e público da informação. In: FUJITA, Mariângela Spotti; MARTELETO, Regina Maria; LARA, Marilda Lopes Gines de (org.). A dimensão epistemológica da ciência da informação e suas interfaces técnicas, políticas e institucionais nos processos de produção, acesso e disseminação da informação. São Paulo: Cultura Acadêmica; Marília: Fundepe, 2008. p. 19-34.

MACHADO, Roberto. Por uma genealogia do poder. In: Foucault, Michel: microfísica do poder. Roberto Machado (Org). 6. ed., Rio de Janeiro: Paz e Terra, 2017. p. VII-XXIII.

MAGALHÃES, Bruno Dias; COELHO, Fernando Souza. Imbricações entre governança pública e governabilidade para a implementação da reforma administrativa: o caso da gestão para a cidadania em Minas Gerais (2011-2014). Revista Gestão \& Planejamento, v. 19, n. 1, p. 350-366, 2018.

MAIA, Antônio Carlos. Sobre a analítica do poder de Foucault. Tempo Social, São Paulo, v.7, n. 1-2, p. 83-103, outubro de 1995.

MINTZBERG, Henry. Criando organizações eficazes: estruturas em cinco configurações. 2. ed. São Paulo: Atlas, 2008.

MOTTA, Alexandre Ribeiro. O combate ao desperdício no gasto público: Uma reflexão baseada na comparação entre os sistemas de compra privado, público federal norte americano e brasileiro. 2010. Dissertação (Mestrado em Desenvolvimento Econômico) - Instituto de Economia, Universidade Estadual de Campinas, São Paulo, 2010. Disponível em:

http://repositorio.unicamp.br/jspui/handle/REPOSIP/285965. Acesso em: 16 mar. 2018.

PERROW, Charles; THOMPSON, James, D.; PETERSON, Richard A. Departmental power and perspective in industrial firms. In: ZALD, Meyer N. (ed.), Power in organizations. Nashville: Vanderbilt University Press, 1970. p. 59-89

SILVA, Nercilene Santos da. Comprar e contratar para uma instituição pública de ciência e tecnologia do setor saúde. 2004. Dissertação (Mestrado 
em Gestão de Ciência e Tecnologia em Saúde) - Escola Nacional de Saúde Pública, Fundação Oswaldo Cruz, Rio de Janeiro, 2004. Disponível em: https://www.arca.fiocruz.br/xmlui/bitstream/handle/icict/5418/663.pdf?sequence =2\&isAllowed=y. Acesso em: 16 fev. 2017.

SILVEIRA, Rafael Alcadipani. Michel Foucault: poder e análise das organizações. Rio de Janeiro: Ed. da FGV, 2005. 168 p.

SILVEIRA, Marceleni Basso da; CAMARGO, Maria Emília. O processo de compras na Prefeitura Municipal de Santa Maria. Qualitas Revista Eletrônica, Campina Grande, Ed. Especial, 2006.

VOLKEMA, Roger; KAPOUTSIS, Ilias; BON, Ana; ALMEIDA, José Ricardo. The influence of power and individualism-collectivism on negotiation Initiation. Revista de Administração Contemporânea, Rio de Janeiro, v. 20, n. 6, p. 673692, nov./dez. 2016.

\title{
The power relationships configuration in purchasing processes at public universities: contribution to the studies of documents and information materiality
}

\begin{abstract}
This paper analyzes power relationships configuring the disciplinary and regulatory mechanisms of purchasing processes at a federal public university, as a contribution to the studies of documentary materiality, in the informational process. Data collection included process mapping, semistructured interviews with civil servants, and gathering of legal and institutional documents standardizing and guiding the workflow. The purchasing process was analyzed and interpreted from two perspectives: Focault's disciplinary view; and documentary view, with an emphasis on Frohmann ideas about the social and material character of information. The analysis of disciplinary power revealed how social practices, institutionalized by documents, produce a set of promising concepts for thinking philosophically about information. Attention to practices and documents reveals how specific documents, in certain moments and places, and in specific areas of the institutional, social and cultural landscape, become informative, materialized and conform as disciplinary mechanisms.
\end{abstract}

Keywords: Purchasing process. Public Universities. Disciplinary Power. Documentation. Information. 